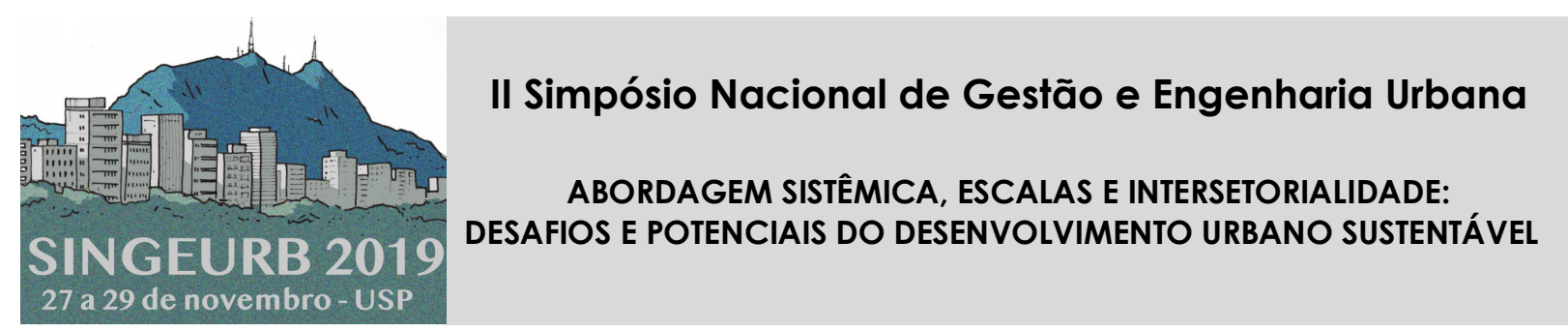

\title{
A Experiência do ciclista no seu percurso ao trabalho: estudo de caso Pelotas-RS. 1
}

\section{The experience of the cyclist on his route to work: case study Pelotas-RS.}

\author{
Hillal, Stéphanie ${ }^{1}$
}

1 Universidade Federal de Pelotas, Rua Benjamin Constant n. 1359, Pelotas, Brasil e stephani.1993@hotmail.com

\begin{abstract}
RESUMO
A prioridade para os carros particulares na cidade torna o uso da bicicleta arriscado. A carência de um sistema viário condizente com as necessidades dos ciclistas nas cidades e a disputa das vias com os veículos faz com que apareçam situações de perigo. Nesse cenário, esta pesquisa pretende investigar o percurso dos ciclistas ao trabalho e os atributos das vias que influenciam nas escolhas das rotas no município de Pelotas. A pesquisa compõe parte da dissertação de mestrado e apresenta resultados parciais. O método de avaliação utilizado foi entrevista "pedalada", no qual o entrevistador acompanhou o percurso realizado pelos participantes ao trabalho, pedalando e gravando o áudio das entrevistas. A partir das análises realizadas, obtiveram-se as conclusões parciais de que os usuários entrevistados não estão satisfeitos com seus trajetos, priorizando a pavimentação e as sinalizações nas escolhas dos percursos. O estudo espera contribuir com pesquisas mais aprofundadas sobre as rotas dos ciclistas e com subsídios para a tomada de decisões mais concisas dos planejadores na necessidade dos ciclistas que utilizam esse meio de transporte diário.
\end{abstract}

Palavras-chave: planejamento urbano, rotas dos ciclistas, mobilidade urbana.

\begin{abstract}
The priority for private cars in the city makes bicycle use risky. The lack of a road system compatible with the needs of cyclists and their dispute against vehicles result in dangerous situations. In this scenario, this research intends to investigate the route of cyclists to work and what influences route choices in Pelotas, Rio Grande do Sul, Brazil. The research composes part of the master's thesis and presents partial results. The evaluation method used was a "bike ride" interview, in which the interviewer followed the participants' route to work on a bicycle, and recorded the audio of the interviews. Based on the analysis, the partial conclusions obtained were that the users interviewed were not satisfied with their routes, prioritizing pavement and traffic signs. The study hopes to contribute in further research on cyclist's routes and to help
\end{abstract}

\footnotetext{
${ }^{1}$ HILLAL, Stéphanie; A Experiência do Ciclista no seu Percurso ao Trabalho: Estudo de Caso Pelotas-RS. In: II SIMPÓSIO NACIONAL DE GESTÃo E ENGENHARIA URBANA: SINGEURB, 2019, São Paulo. Anais... Porto Alegre: ANTAC, 2019.
} 
planners to make more concise decisions on the need of cyclists using this daily means of transport.

Keywords: Urban planning, cyclist's routes, urban mobility.

\section{INTRODUÇÃO}

Com o aumento da circulação de automóveis também ocorreu um elevado número de acidentes. As pessoas perderam o prazer em andar na cidade, enquanto o desejo de fugir dos estacionamentos, ruídos e da poluição se tornou crescente. Ciclistas se deslocam com medo dos acidentes cada vez mais comuns (GEHL, 2012).

O uso da bicicleta traz inúmeros benefícios, aumentando a inclusão social, o aproveitamento do espaço urbano, menos congestionamentos e consequentemente, menos acidentes de trânsito. Isso gera uma maior saúde pública e reduz a emissão de gases polventes (KUIJPER e BRAAKMAN, 2009).

Sendo assim, é necessário executar um sistema viário que seja condizente com as necessidades desse modo de transporte, sendo proporcionada uma mobilidade de qualidade aos cidadãos. A construção de ciclovias para o lazer não auxilia as pessoas que utilizam a bicicleta como meio de transporte, pois são construídas longe das rotas e necessidades dos usuários (QUADRADO, 2018).

\section{OBJETIVO}

O objetivo desta pesquisa é analisar quais são os fatores que influenciam a decisão de escolha dos percursos e os atributos necessários para que o sistema viário comporte as necessidades dos usuários de bicicleta nos percursos ao trabalho diariamente.

Considerando que grande parte das rotas disponíveis para os ciclistas nos centros urbanos não apresenta a infraestrutura adequada ao uso para as quais são destinadas, tem-se a intenção de analisar quais são os percursos utilizados por aqueles que usam a bicicleta como um meio de transporte ao trabalho. Verificados os atributos relacionados ao conforto e segurança, que interferem e influenciam na escolha dos ciclistas para traçarem as rotas de que usufruem. A pesquisa igualmente visou analisar como os usuários desse sistema os avaliam, perante a aplicação de entrevistas abertas.

\subsection{Fatores e interferências na escolha da rota ciclística}

Conforme Beheshyitabar (2014), uma análise das rotas com base em conforto e segurança deve ser feita considerando fatores que contribuem diretamente em questões comportamentais. Essa análise tem relação com o tipo de deslocamento a ser feito, assim como, com as características encontradas na via, com a organização do tráfego, com o espaço no qual está inserido e com o usuário da bicicleta.

Os fatores relacionados como mais importantes na influência do comportamento ao determinar o percurso são o tempo de viagem e a distância percorrida (SENER et al., 2009; MENGHINI et al., 2010; BEHESHYTABAR, 2014; SONG, 2016). Há uma relação entre esses itens, já que, indiretamente, a distância a ser percorrida influi no tempo de deslocamento. Na maioria das situações, os ciclistas buscam diminuir esse período utilizado para locomoção, sendo que esse é um consenso entre as pessoas, independentemente do meio em que ocorre tal deslocamento.

Algumas características de que a pista dispõe são de destaque em relação ao grau de influência, como a largura da via que é dada pela distância entre o meio-fio da calçada ou o ponto ao lado dos carros estacionados - até a linha que faz a delimitação do final da faixa. Outro item a ser considerado é a pavimentação, cuja contribuição é observada na segurança, no conforto e na convivência entre os ciclistas (SORTON; WALSH, 1994; EPPERSON, 
1994; LANDIS et al., 1997; KUIJPER e BRAAKMAN-2009). O pavimento a ser utilizado nas vias pelos ciclistas denota bastante cuidado, já que é um fator que pode tornar a via mais atrativa ao gosto daqueles que utilizam a infraestrutura.

Os cruzamentos constituem outro item que requer bastante cuidado e importância, pois a quantidade excessiva de cruzamentos ao longo dos percursos inibe o uso dos mesmos. Geralmente, as sinalizações para que o ciclista "pare" acabam representando uma interrupção no decorrer da rota, gerando um desgaste maior em função de parar e retomar o esforço (STINSON; BATH, 2003, 2004; BROACH, 2011). Normalmente, os ciclistas preferem rotas com pouco volume de tráfego, o que reduz os riscos de acidentes. Percebeu-se que o grande volume de tráfego diminui a sensação de segurança na escolha da rota (SONG, 2016).

\subsection{Rotas cicloviárias na cidade de Pelotas}

Para aplicar os objetivos da pesquisa proposta, foi escolhida como estudo de caso a cidade de Pelotas, Rio Grande Do Sul, Brasil. Trata-se de uma cidade com população estimada em 341.648 habitantes (IBGE-2018), constituída em sua maioria por jovens e estudantes e com 93.3\% da sua população urbana (IBGE-2018). A cidade é privilegiada por possuir um terreno relativamente plano, o que propicia o uso da bicicleta. Esse sistema cicloviário de Pelotas é constituído por ciclovias e ciclofaixas, sendo que já nas últimas obras realizadas de infraestrutura urbana, foi adotada a utilização de uma ciclovia, por exemplo, como ocorre na Avenida Juscelino Kubitschek conforme Figura 1.

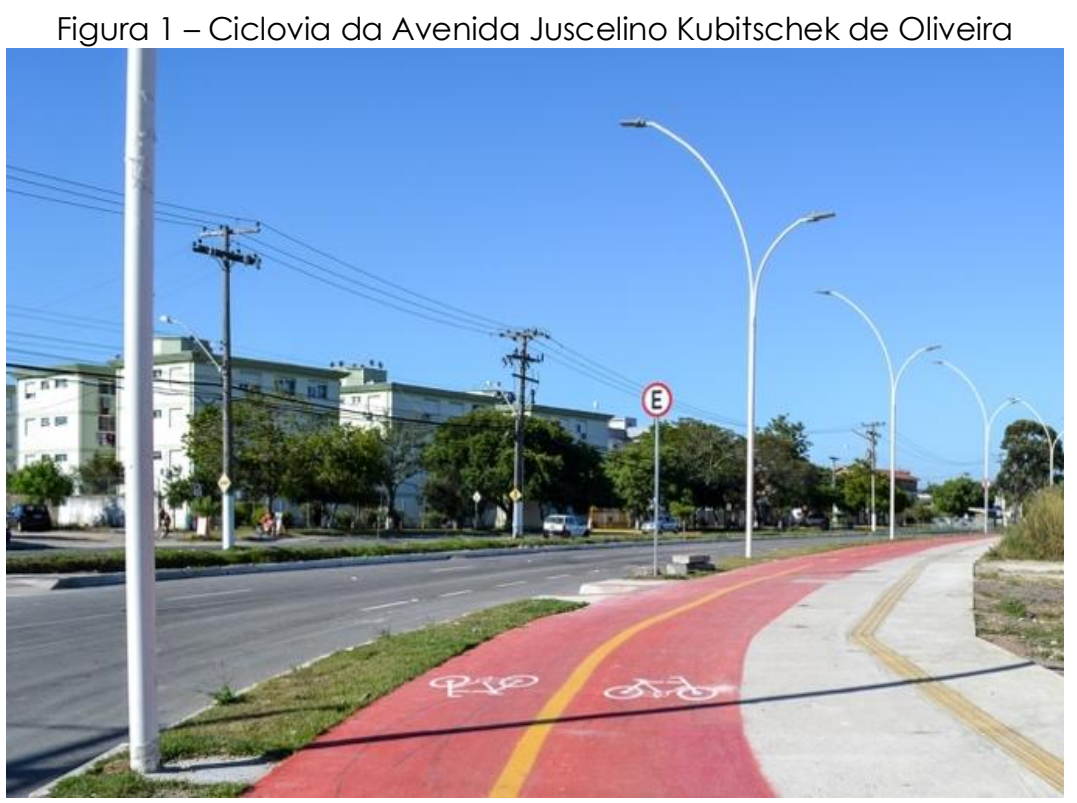

Fonte: Autor (2017)

\section{METODOLOGIA}

Com a intenção de atingir os objetivos propostos por esta pesquisa, o estudo foi estruturado em quatro etapas realizadas durante seis meses. Essa composição metodológica foi conduzida por: revisão bibliográfica; aplicação de entrevistas abertas; levantamento e organização da base de dados onde foram realizadas as transcrições das entrevistas; organização dos áudios e imagens obtidas; e análises qualitativas dos resultados para elaboração do artigo.

O método de avaliação utilizado foi entrevista "pedalada", ou seja, o entrevistador percorreu o trajeto ao trabalho dos entrevistados pedalando ao lado e gravando seu áudio. Foi utilizado 
o seguinte método, por possuir maior clareza dos relatos e as opiniões dos usuários sobre as condições das vias.

Juntamente a isto, foram realizadas fotos documentais dos relatos recebidos e utilização do aplicativo Strava para captar a rota percorrida. Foram realizadas 25 entrevistas, que duraram em média de 15 a 20 minutos, com pessoas selecionadas em grupos de ciclistas no Facebook. Foi utilizada essa rede social online devido à praticidade ao encontrar os usuários desse meio de transporte em grupos existentes.

\section{ANÁLISES DOS RESULTADOS}

Após realização das 25 entrevistas, como citado na metodologia, constatou-se que as características da via são fatores importantes nas decisões das rotas dos ciclistas nos seus percursos ao trabalho. O ponto positivo deste estudo é que a partir da coleta de dados como esta, é possível descobrir quais são os atributos necessários para que o sistema viário comporte as necessidades dos usuários de bicicleta como meio de transporte.

Cerca de 18 ciclistas responderam que o volume de tráfego é um dos mais importantes atributos, pois influencia diretamente com relação à sensação de segurança na rota. Além disso, foi comentado por 13 ciclistas que a distância e o tempo são bastante relevantes em suas decisões.

Essa rota eu escolhi pois prefiro andar na mesma mão que os carros, me sinto mais seguro, não sei se estou certo ou errado. Nesse trecho fica mais perigoso de alguém abrir alguma porta e me atingir, mas mesmo assim me sinto mais seguro. Escolhi a Rua Almirante Barroso, mesmo sendo de fluxo intenso, pois não pego nenhum cruzamento e possui bastante sinalizações. (ENTREVISTADO-1)

Neste trecho transcrito, percebe-se a discordância com a bibliografia de Song (2016), que afirma que o volume de tráfego reduz a sensação de segurança na escolha da rota. Mesmo o volume de tráfego sendo maior, foram utilizadas as rotas com maior volume de tráfego, pois o fator sinalizações e sentido do fluxo torna-se mais importante para sua sensação de segurança, conforme Figura 2.

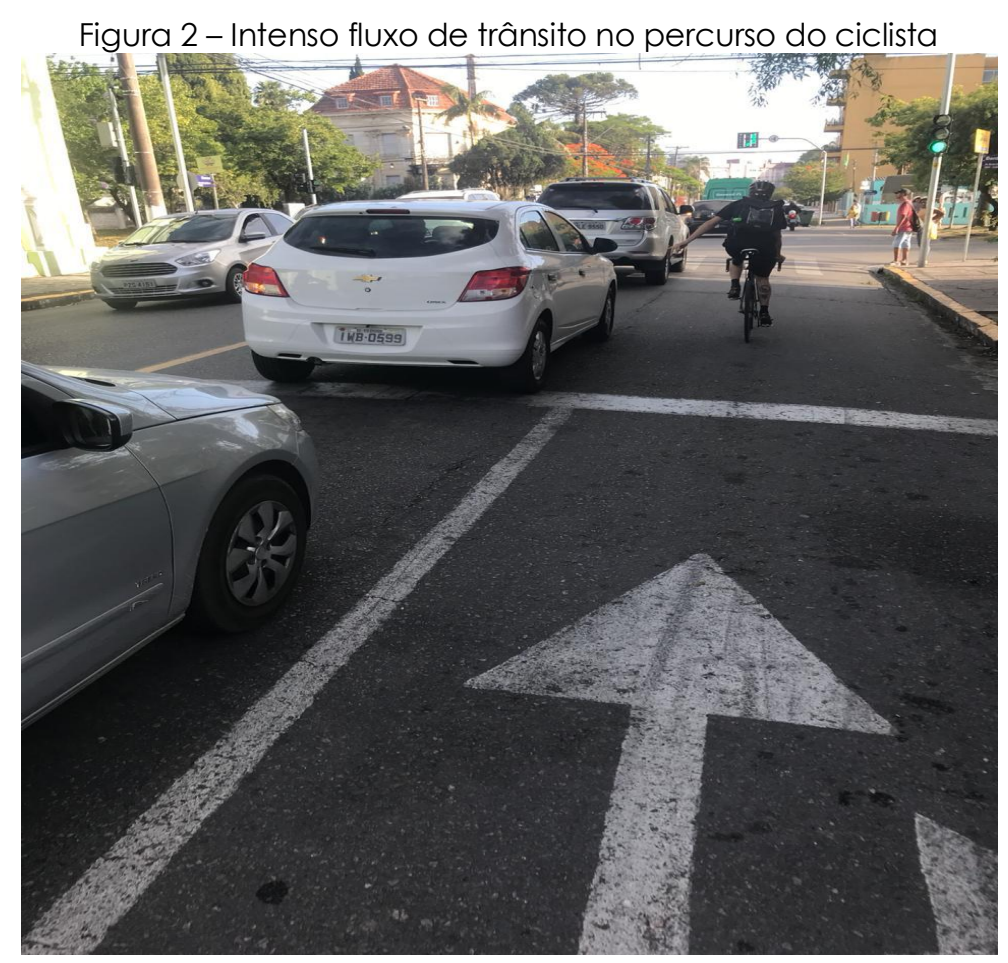

Fonte: Autor (2018) 
Ao total, 15 pessoas reclamaram sobre as sinalizações das vias e relacionaram com a possibilidade de acidentes, colocando suas vidas em risco. Não ocorreram reclamações quanto à largura da via, apenas em relação à distância com que os veículos ultrapassavam os ciclistas, a qual causava situações de desconforto e perigo de acidentes. Em relação aos cruzamentos, cerca de 8 ciclistas mencionaram que deveria haver melhor sinalização para reduzir os conflitos gerados. Isso corrobora as teorias de Stinson e Bath $(2003,2004)$ e de Broach (2010), as quais afirmam que as quantidades excessivas de cruzamentos inibem o uso dos mesmos.

A qualidade da pavimentação foi citada por 21 ciclistas, como sendo um fator que interfere diretamente na escolha das rotas e no tempo de deslocamento:

Como passa muitos ônibus no trecho que utilizo, o asfalto está bastante danificado, tornando o trajeto complicado. A pavimentação é um ponto importante na escolha da minha rota. Os corredores de ônibus são bem complicados pois não sabemos por onde andar, se dentro ou fora, disputando espaço com os carros. Andar rente aos carros é complicado pois posso acabar sendo atingida pela porta ao abrir. (ENTREVISTADA-3)

Essa contribuição é observada na segurança, no conforto e na convivência entre os ciclistas e é sustentada por Sorton e Walsh (1994), Epperson e Davis (1994) e Landis et al (1997) como sendo um fator que torna mais atrativo para aqueles que utilizam a pavimentação, conforme Figura 3.

Figura 3 - Presença de buracos na via onde o ciclista é obrigado a desviar

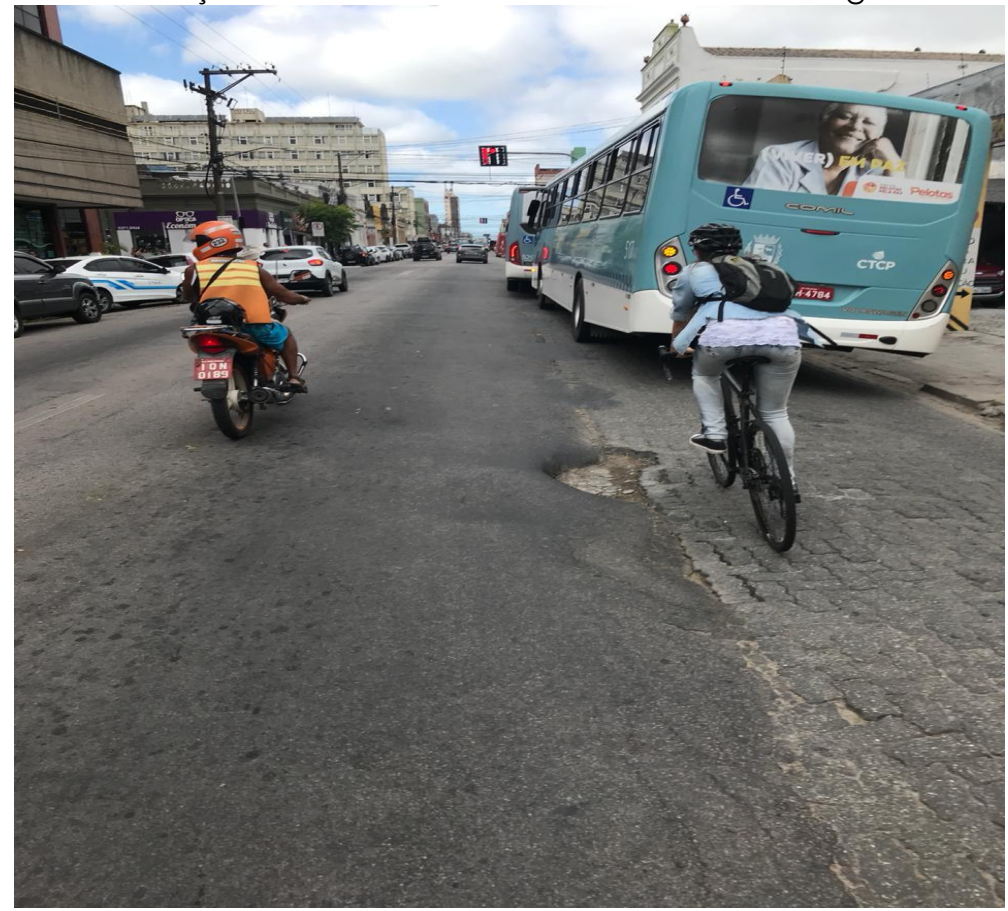

Fonte: Autor (2018)

Com os relatos transcritos, foi possível identificar os percursos utilizados e analisar as características urbanas do sistema cicloviário atual. A partir das imagens, pode-se ver que o planejamento urbano não comporta a realidade dos ciclistas no total de seus trajetos ao trabalho. Por fim, mesmo com todas as adversidades, constatou-se que nenhum ciclista deixaria de utilizar esse meio de transporte ao trabalho.

\section{CONCLUSÕES}

A partir das análises realizadas, conclui-se que os usuários entrevistados não estão satisfeitos com seus trajetos, mesmo não deixando de utilizar esse meio de transporte. Muitos percursos 
são escolhidos por possuírem a pavimentação menos deteriorada, as melhores sinalizações, e o mesmo sentido do fluxo de tráfego dos veículos, segundo itens de avaliação anteriormente citados. Esses resultados fornecem subsídios para investigações mais profundas, com uma amostragem quantitativa, tornando a tomada de decisões dos planejadores mais adequada, levando em conta as necessidades dos ciclistas que utilizam esse meio de transporte diário na cidade de Pelotas. Além disso, serve para enaltecer a importância desse meio de transporte para que ocorram mudanças na qualidade de vida das cidades e do meio ambiente.

Os resultados parciais obtidos pela pesquisa, através das entrevistas, demonstram a necessidade que as cidades têm de melhorar sua infraestrutura viária e criarem maior rede cicloviária para que os usuários deste modal de transporte transitem em segurança. Além disso, investimentos nessas estruturas de melhoramentos das sinalizações, pavimentações, ciclovias e ciclofaixas, incentivam o uso da bicicleta por cada vez mais pessoas. Por isso, esta pesquisa merece ser aprofundada, pois conhecendo a real rota e suas características, os ciclistas poderão utilizar esse meio de transporte com maior frequência e segurança. Só assim, teremos menos acidentes de trânsito e congestionamentos, devido ao uso exagerado nos carros nas cidades.

\section{REFERÊNCIAS}

BEHESHYITABAR, E. et al. Route Choice Modelling for Bicycle Trips. International Journal for Traffic and Transport Engineering, 2014, 4(2), p.194-209, 2014. Disponível em http://ijtte.com/uploads/2014-06-09/935be804-7c29-708alJTTE_Vol\%204(2)_6.pdf. Acesso em out. 2018.

BROACH, J.; GLIEBE J.; DILL J. Bicycle route choice model developed using revealed preference GPS data. 90th Annual Meeting of the Transportation Research Board, 2011.

EPPERSON, B. Evaluating suitability of roadways for bicycle use: toward a cycling level of service standard. Transportation Research Record, 1438, 9-16. 1994.

GEHL, J. Cidade Para Pessoas. 1. Ed. São Paulo: Perspectiva, 2012.

IBGE. Sinopse do Censo Demográfico. 2010. Disponível em

https://cidades.ibge.gov.br/brasil/rs/pelotas/panorama. Acesso em out. 2018.

KUIJPER; BRAAKMAN. Cycling - Inclusive Policy Development: A Handbook. Ultrecht, The Netherlands, 2009. Disponível em

https://www.sutp.org/files/contents/documents/resources/H_Training-Material/Cycling

Handbook - Chapters/GIZ_SUTP_CIP_5-Five-main-requirements-for-cycling-inclusive-

infrastructure_EN.pdf. Acesso em out. 2018.

LANDIS, B. W.; VATTICUTI, V. R.; BRANNICK, M.T. Real time human perceptions: toward a Bicycle level of servisse. Transportation Research Record, 1578, 1997.

MENGHINI, G. et al. Route choice of cyclists in Zurich. Transportation Research Part A, $n^{\circ} 44, p$. 754-765, 2010.

QUADRADO, C. A. Rotas de ciclistas no ambiente urbano: fatores decisivos para a escolha de percursos na cidade de Rio Grande - RS. 2018. Dissertação (Mestrado em Arquitetura e Urbanismo) - Programa de Pós-Graduação em Arquitetura e Urbanismo, Faculdade de Arquitetura e Urbanismo, Universidade Federal de Pelotas, Pelotas, 2018.

SEGADILHA, A.B.P. Identificação dos Fatores que Influenciam na Escolha da Rotas pelos 
Ciclistas: estudo de caso da cidade de São Carlos. 2014. Dissertação (Mestrado em Engenharia Urbana) - Pós-Graduação em Engenharia Urbana, Universidade Federal de São Carlos, São Paulo. 2014.

SENER, i. N. et al. An Analysis of Bicyclists and Bicycling Characteristics: Who, Why, and How Mucch are they Bicycling? Transportation Research Record: Journal of the Transportation Research Board, $n^{\circ} 2134$, p. 63-72, 2009. Disponível em

https://www.researchgate.net/publication/274603165_Who_Are_Bicyclists_Why_and_How_M uch_Are_They_Bicycling. Acesso em out. 2018.

SONG, R. et al. Understanding cyclists' risky route choice behavior on urban road sections. Transportation Research Procedia, 25, p. 4157-4170, 2016.

SORTON, A.; WALSH, T. Bicycle Stress Level as a Tool to Evaluate Urban and Suburban Bicycle Compatibility. Transportation Research Record. 1438. 1994, pp. 17-24.

STINSON, M. A.; BATH C. R. An Analysis of Commuter Bicyclist Route Choice Using a Stated Preference Survey. Transportation Research Record: Journal of the Transportation Research Board, $n^{\circ} 182$, p. 107-115, 2003. Disponível em https://pdfs.semanticscholar.org/646e/08bdd3180da839d93293a9b8e98ee39a036f.pdf. Acesso em out. 2018. 